\section{(6) OPEN ACCESS}

\title{
Altered DNA methylation in children born to mothers with rheumatoid arthritis during pregnancy
}

\author{
Hilal Ince-Askan, ${ }^{1}$ Pooja R Mandaviya, ${ }^{2}$ Janine F Felix, ${ }^{3,4,5}$ Liesbeth Duijts, ${ }^{3,6,7}$ \\ Joyce B van Meurs, ${ }^{2}$ Johanna M W Hazes, ${ }^{1}$ Radboud J E M Dolhain ${ }^{1}$
}

\begin{abstract}
Handling editor Josef $S$
Smolen

- Additional material is published online only. To view please visit the journal online (http://dx.doi.org/10.

1136annrheumdis-2018214930).
\end{abstract}

For numbered affiliations see end of article.

\section{Correspondence to}

Hilal Ince-Askan, Rheumatology,

Erasmus Medical Centre,

Rotterdam 3000 CA, The

Netherlands;

h.ince-askan@erasmusmc.nl

Received 16 December 2018

Revised 17 April 2019

Accepted 7 May 2019

Published Online First

29 May 2019

\section{Check for updates}

(C) Author(s) (or their employer(s)) 2019. Re-use permitted under CC BY. Published by BMJ.

To cite: Ince-Askan $\mathrm{H}$ Mandaviya PR, Felix JF, et al. Ann Rheum Dis 2019;78:1198-1204.

\section{ABSTRACT}

Objectives The main objective of this study was to determine whether the DNA methylation profile of children born to mothers with rheumatoid arthritis (RA) is different from that of children born to mothers from the general population. In addition, we aimed to determine whether any differences in methylation are associated with maternal RA disease activity or medication use during pregnancy.

Methods For this study, genome-wide DNA methylation was measured at cytosine-phosphateguanine ( $\mathrm{CpG}$ ) sites, using the Infinium Illumina HumanMethylation 450K BeadChip, in 80 blood samples from children (mean age $=6.8$ years) born to mothers with RA. As controls, blood samples from 354 children (mean age $=6.0$ years) from the population-based Generation R Study were used. Linear mixed models were performed to investigate differential methylation between the groups, corrected for relevant confounders. Results A total of 147 CpGs were differentially methylated between blood samples of children born to mothers with RA and the control blood samples. The five most significantly associated $\mathrm{CpG}$ s were cg06642177, cg08867893, cg06778273, cg07786668 and cg20116574. The differences in methylation were not associated with maternal RA disease activity or medication use during pregnancy.

Conclusions DNA methylation at 147 CpGs differed between children born to mothers with RA and children born to mothers from the general population. It remains unknown whether the identified associations are causal, and if so whether they are caused by the disease or treatment. More research, including replication of these results, is necessary in order to strengthen the relevance of our findings for the later-life health of children born to mothers with RA.

Adverse exposures in early life are associated with later-life health, which is referred to as the developmental origins of health and disease hypothesis. $^{1-5}$ Epigenetic processes are thought to be one of the mechanisms underlying the associations of early-life exposures and later-life health outcomes. ${ }^{67}$ DNA methylation is the best studied and understood epigenetic modification. ${ }^{89}$ Factors that have been demonstrated to be associated with fetal DNA methylation include maternal disease, ${ }^{7}$ malnutrition, ${ }^{10-13}$ smoking, ${ }^{14}$ placental insufficiency, ${ }^{15}$ corticosteroids, ${ }^{16}$ folate depletion ${ }^{17}$ and cytokines. ${ }^{18}$ DNA methylation usually occurs at cytosine-phosphate-guanine (CpG) sites. ${ }^{8} 9$ The effect of hypermethylation and hypomethylation on

\section{Key messages}

What is already known about this subject?

- Adverse exposures in early life are associated with later-life health.

- Epigenetic changes are thought to be one of the underlying mechanisms.

- There is not much known about the consequences of maternal rheumatoid arthritis (RA) on the offsprings' long-term health.

What does this study add?

- DNA methylation is different in children born to mothers with RA compared with mothers from the general population.

How might this impact on clinical practice or future developments?

- Maternal RA disease during pregnancy might have lifelong consequences for the offspring.

- More research in this particular field must be undertaken.

gene expression depends on the CpG location. ${ }^{19} 20$ The most pronounced changes in DNA methylation occur during early pregnancy. ${ }^{711}$

During embryogenesis, there are three germ layers that form in the developing fetus (ectoderm, mesoderm and endoderm). When DNA methylation is altered in early pregnancy, all germ layers are affected. ${ }^{21} 22$

Rheumatoid arthritis (RA) may be considered as an adverse exposure during pregnancy. ${ }^{23}$ Therefore, it is plausible that maternal RA may induce changes in fetal DNA methylation, and that it is related with the later-life health of the offspring. Interleukin-6 is known to influence DNA methylation. ${ }^{18}$ RA treatment during pregnancy includes among others sulfasalazine (SSZ) and corticosteroids such as prednisone. SSZ is a known folate antagonist that crosses the placenta and could influence DNA methylation in this respect. ${ }^{17}{ }^{24}$ Furthermore, corticosteroids might influence DNA methylation. ${ }^{16}$ Especially during early pregnancy, when the placenta is not completely developed, prednisone passively diffuses to the fetus. ${ }^{25-28}$

In the current study we investigated whether the DNA methylation profile of children born to mothers with RA was different from that of children born to mothers from the general population. Furthermore, we investigated whether any differentially methylated CpGs were associated 
with RA disease activity or medication use during pregnancy, or with indicators of future metabolic and cardiovascular diseases. In addition, we examined whether these CpGs were associated with the expression of genes using expression quantitative trait methylation (eQTM) analysis.

\section{METHODS}

\section{Study population}

FEPRA study

This study is embedded in the Pregnancy-induced Amelioration of Rheumatoid Arthritis (PARA) study, a prospective cohort study on pregnancy and RA. ${ }^{29}$ From 2002 to 2008, 369 female patients with RA who had a wish to conceive (or already pregnant) were enrolled. ${ }^{30}$ After participation in the PARA study, 196 children and their parents were invited to participate in a follow-up study, the FEtal Programming in Rheumatoid Arthritis (FEPRA) study. For this study, 108 children with a mean age of 6.8 years $(\mathrm{SD}=1.3)$ visited Erasmus Medical Centre in Rotterdam, and the parents of 85 children (all of European ancestry) gave informed consent for studies on DNA methylation of their children. Furthermore, the parents of 71 children provided cheek swabs from their children. There were no statistical differences in baseline characteristics between the participating and non-participating group.

\section{Generation R Study}

The control group consisted of children with a mean age of 6.0 years $(S D=0.4)$, included in the Generation $\mathrm{R}$ Study, a population-based prospective cohort study from pregnancy onwards in Rotterdam, the Netherlands. ${ }^{32}$ In this study, all pregnant women living in Rotterdam with a delivery date between April 2002 and January 2006 were invited to participate, and 9778 mothers were enrolled. ${ }^{32}$ At the age of 6 years, DNA methylation was measured in a subgroup of 493 children of European ancestry.

\section{Data collection}

FEPRA study

In the PARA study, data on mother (eg, disease activity (with the Disease Activity Score in 28 joints using $\mathrm{C}$ reactive protein levels, DAS28-CRP $\left.{ }^{3}\right)$ ) and child were collected. ${ }^{31}$ For the FEPRA study, data on blood pressure, growth and body composition of the children were measured. Also, blood, which is a mesoderm germ layer derivate, was drawn for DNA methylation analysis. ${ }^{33}$ Cheek swabs were collected for the analysis of DNA methylation in buccal epithelial cells, which is an ectoderm germ layer derivate.

\section{Generation R Study}

In the Generation R Study, mothers were seen three times during pregnancy. The children were followed from birth until childhood. Data collection in children and their mothers included questionnaires, detailed physical examinations and blood sampling. 32

\section{DNA methylation analysis}

Genomic DNA was extracted from whole peripheral blood samples and from the cheek swab samples. Bisulfite conversion of 500 ng of genomic DNA was performed using the Zymo EZ-96 DNA Methylation Kit (Zymo Research, Irvine, California, USA) according to the manufacturer's protocol.

Genomic methylation profiling was performed using the Infinium Illumina HumanMethylation 450K BeadChip arrays (Illumina, San Diego, USA) according to the manufacturer's protocol. The Illumina array measures methylation status of 485 $512 \mathrm{CpG}$ sites in the gene and non-gene regions across the entire human genome. To prevent possible batch effects, blood and cheek swab samples were measured in the same run.

\section{Quality control and normalisation}

The data were preprocessed using the minfi package in R V.3.4.1 (www.r-project.org). Samples with incomplete or poor bisulfite conversion, extension, hybridisation or specificity were excluded. ${ }^{34}$ In addition, samples with sex mismatch and samples with a call rate $<95 \%$ were removed. This quality control (QC) was done separately for blood samples and for cheek swab samples. During QC, 5 blood and 14 cheek swab samples from the FEPRA study were excluded, resulting in 80 and 57 samples, respectively. From the Generation R blood samples, 27 were excluded due to corticosteroid use or RA disease in the mother, and 32 were excluded during QC, resulting in 441 blood samples. In addition, 87 cases with missing data from the Generation $\mathrm{R}$ Study were excluded, leaving 354 samples to analyse. The intensity values were then quantile normalised using the incorporating Control Probe Adjustment and reduction of global CORrelation (CPACOR) workflow. ${ }^{34}$ Methylation at each CpG was calculated as the beta value (beta=intensity of the methylated allele (M)/ (intensity of the unmethylated allele $(U)+M+100)$ ), containing values from 0 to 1 . Blood cell composition of the samples was estimated using the Houseman method with the Reinius reference set. ${ }^{35} 36$ The Reinius reference set is not yet validated in children. However, it is the best method available, and it has been used in other epigenetic studies in children. ${ }^{37} 38$ Probes with single nucleotide polymorphisms (SNPs) at single base extension, probes with improper binding, and CpGs on the $\mathrm{X}$ and $Y$ chromosome were removed from the analysis. ${ }^{37-40}$ From the initial 485512 CpGs, 32057 were excluded during QC, leaving $453456 \mathrm{CpGs}$ for analysis.

\section{Statistical analysis}

For all subjects, descriptive statistics were calculated using Stata V.14.1 (https://www.stata.com/stata14/). Student's t-tests and $\chi^{2}$ tests were used to compare the baseline characteristics. For these analyses, $\mathrm{p}$ values $<0.05$ were considered statistically significant.

Linear mixed models were performed to analyse differential methylation between the groups, using R. The first model was created to compare the blood samples from the FEPRA study with the blood samples of the Generation R Study to determine whether the DNA methylation profile of children born to mothers with RA was different from that of children born to mothers from the general population. This model was corrected for biological covariates (age, body mass index (BMI) SD scores (SDS), adjusted for age and sex according to the Dutch reference values, using the Growth Analyser (V.4.0; Growth Analyser, Rotterdam, the Netherlands, www.growthanalyser.org,) sex, gestational age at delivery, maternal age, folic acid use during pregnancy, socioeconomic status (SES), maternal smoking and white blood cell subtypes), technical covariates (technical batch effects (array identifier (ID) and position on array)) and five hidden confounders. Technical covariates were added as random effects in the models. The hidden confounders were calculated using the CATE package ${ }^{4142}$ while correcting for the group (RA vs non-RA offsprings), all biological covariates and technical covariates. This resulted in hidden confounders that were independent of all included covariates. The BACON package ${ }^{42}$ was used to correct for unobserved covariates in order to reduce test statistic bias and inflation. The genomic inflation factor 
$(\lambda)^{43}$ was calculated. After QC, 453456 CpGs remained for analysis. Therefore, a Bonferroni-adjusted $\mathrm{p}$ value of $0.05 / 453$ $456=1.10 \times 10^{-7}$ was used. $^{44}$

CpGs were annotated for nearby genes with the Genomic Regions Enrichment of Annotations Tool, ${ }^{45}$ a general method to present epigenetic data. ${ }^{373840}$ Significant CpGs from the first analysis were then further analysed within the blood samples of the FEPRA study to explore if RA disease activity, prednisone use or SSZ use during pregnancy would explain the differences in methylation found in the first model. After that, two linear mixed models were created with the significant CpGs to identify whether these were associated with the BMI SDS or the fat percentage SDS of the child, as indicators of future metabolic disease. These models were analysed in the 80 blood samples of the FEPRA study. CpGs with a p value below $0.05 / 147=3.4 \times 10^{-4}$ were considered statistically significant.

The significant $\mathrm{CpG}$ s found in the first analysis were also analysed in DNA derived from buccal epithelial cells, obtained by cheek swabs from the FEPRA study, to explore if the differentially methylated CpGs were also differentially methylated in that germ layer derivate, as a kind of validation of the results. For this analysis, $\mathrm{CpG}$ with a $\mathrm{p}$ value below significance level of $3.4 \times 10^{-4}$ were considered statistically significant.

\section{eQTM analysis}

eQTMs are sites at which DNA methylation is known to influence the expression of one or more genes. ${ }^{46}$ To analyse whether any of the significant CpGs were linked to the expression of nearby genes, an eQTM analysis was performed. For these analyses the online BIOS QTL browser (https://molgenis26.target. rug.nl/downloads/biosqtlbrowser/) was used. ${ }^{39}$

\section{RESULTS}

\section{Participants}

The flow chart of the study population is shown in figure 1. A total of 80 blood and 57 cheek swab samples from the FEPRA study (children born to mothers with RA) and 354 blood samples from the Generation R Study (children born to mothers from the general population) remained for analysis.

Descriptive statistics of the study population are presented in table 1. Overall, children from the FEPRA study were slightly older compared with children in the Generation $\mathrm{R}$ Study $(\mathrm{p}<0.001)$. In the FEPRA study, $45 \%$ of the women did not

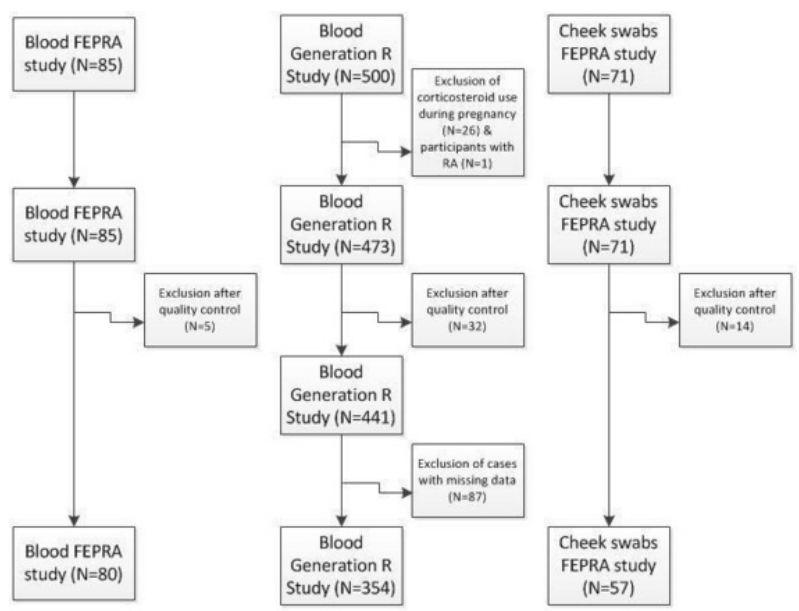

Figure 1 Flow chart of the study population and exclusion of participants. FEPRA, FEtal Programming in Rheumatoid Arthritis; RA, rheumatoid arthritis.

\begin{tabular}{|c|c|c|}
\hline & $\begin{array}{l}\text { FEPRA study } \\
(\mathrm{n}=80)\end{array}$ & $\begin{array}{l}\text { Generation R } \\
\text { Study }(\mathrm{n}=354)\end{array}$ \\
\hline Age child* (years), mean (SD) & $6.8(1.3) \dagger$ & $6.0(0.4) \dagger$ \\
\hline BMI SDS child, ${ }^{*}$ mean (SD) & $-0.14(0.87) \dagger$ & $0.18(0.74) \dagger$ \\
\hline \multicolumn{3}{|l|}{ Sex of the child } \\
\hline Male, n (\%) & $46(57.5)$ & $176(49.7)$ \\
\hline Female, $n(\%)$ & $34(42.5)$ & $178(50.3)$ \\
\hline $\begin{array}{l}\text { Maternal age at delivery (years), mean } \\
\text { (SD) }\end{array}$ & $32.9(3.9)$ & $32.5(4.0)$ \\
\hline Gestational age (weeks), mean (SD) & $39.5(2.0) \dagger$ & $40.2(1.5) \dagger$ \\
\hline Gestational age $<37$ weeks, n (\%) & $8(10.0) \dagger$ & $6(1.7) \dagger$ \\
\hline \multicolumn{3}{|l|}{ Folic acid } \\
\hline Start before pregnancy, $\mathrm{n}(\%)$ & $25(31.3) \dagger$ & $212(59.9) \dagger$ \\
\hline Start in early pregnancy, $\mathrm{n}(\%)$ & $19(23.8) \dagger$ & $116(32.8) \dagger$ \\
\hline No use, $\mathrm{n}(\%)$ & $36(45.0) \dagger$ & $26(7.3) \dagger$ \\
\hline \multicolumn{3}{|l|}{ SES based on educational level } \\
\hline Low, n (\%) & $9(11.3) \dagger$ & $4(1.1) \dagger$ \\
\hline Middle, $\mathrm{n}(\%)$ & $33(41.3) \dagger$ & $108(30.5) \dagger$ \\
\hline High, $\mathrm{n}(\%)$ & $38(47.5) \dagger$ & $242(68.4) \dagger$ \\
\hline Maternal smoking, $\neq \mathrm{n}(\%)$ & $1(1.3) \dagger$ & $86(24.3) \dagger$ \\
\hline $\begin{array}{l}\text { DAS28-CRP(3) third trimester, mean } \\
\text { (SD) }\end{array}$ & $3.3(1.1)$ & - \\
\hline \multicolumn{3}{|l|}{ Use of medication $\geq 1$ trimester } \\
\hline Only prednisone use, $\mathrm{n}(\%)$ & $17(21.3)$ & - \\
\hline Only sulfasalazine use, $\mathrm{n}(\%)$ & $14(17.5)$ & - \\
\hline Combination, $\mathrm{n}(\%)$ & $13(16.3)$ & - \\
\hline \multicolumn{3}{|l|}{ Prednisone dose (mg), median (IQR) } \\
\hline First trimester & $7.5(2.5-10.0)$ & - \\
\hline Second trimester & $7.5(5.0-10.0)$ & - \\
\hline Third trimester & $6.3(5.0-10.0)$ & - \\
\hline No medication use, $\mathrm{n}(\%)$ & $36(45.0)$ & - \\
\hline Fat percentage SDS, mean (SD) & $0.24(0.97)$ & - \\
\hline \multicolumn{3}{|c|}{$\begin{array}{l}\text { *At time of the blood sampling. } \\
\dagger P<0.001 \text {. } \\
\text { †During pregnancy. } \\
\text { BMI, body mass index; DAS28-CRP(3), Disease Activity Score in } 28 \text { joints using C } \\
\text { reactive protein levels; FEPRA, FEtal Programming in Rheumatoid Arthritis; SDS, SD } \\
\text { score; SES, socioeconomic status. }\end{array}$} \\
\hline
\end{tabular}

start using folic acid before or in early pregnancy compared with $92.7 \%$ in the Generation R Study $(\mathrm{p}<0.001)$. Approximately half of the women (47.5\%) from the FEPRA study had a high SES compared with $68.4 \%$ of the women from the Generation R Study ( $\mathrm{p}<0.001)$. One woman $(1.3 \%)$ from the FEPRA study and 86 women $(24.3 \%)$ from the Generation R Study smoked periconceptionally or at any time during pregnancy $(\mathrm{p}<0.001)$.

\section{DNA methylation analysis}

In the first linear mixed model, blood samples from the FEPRA study were compared with blood samples from the Generation R Study, corrected for the covariates mentioned in the Methods section. In total, $147 \mathrm{CpGs}$ were significantly differentially methylated between children in the FEPRA study and children in the Generation R Study (figure 2). The QQ plot is shown in figure 3 . The genomic inflation factor $(\lambda)$ was 1.06 .

In table 2 the five most significant $\mathrm{CpGs}$ and the five $\mathrm{CpGs}$ with the largest effect sizes (within the significant $\mathrm{CpGs}$ ) are described in detail. The complete list of significantly associated CpGs is provided as an online supplementary file. A positive beta represents higher methylation levels in children born to mothers with RA. Methylation was higher in children born to 


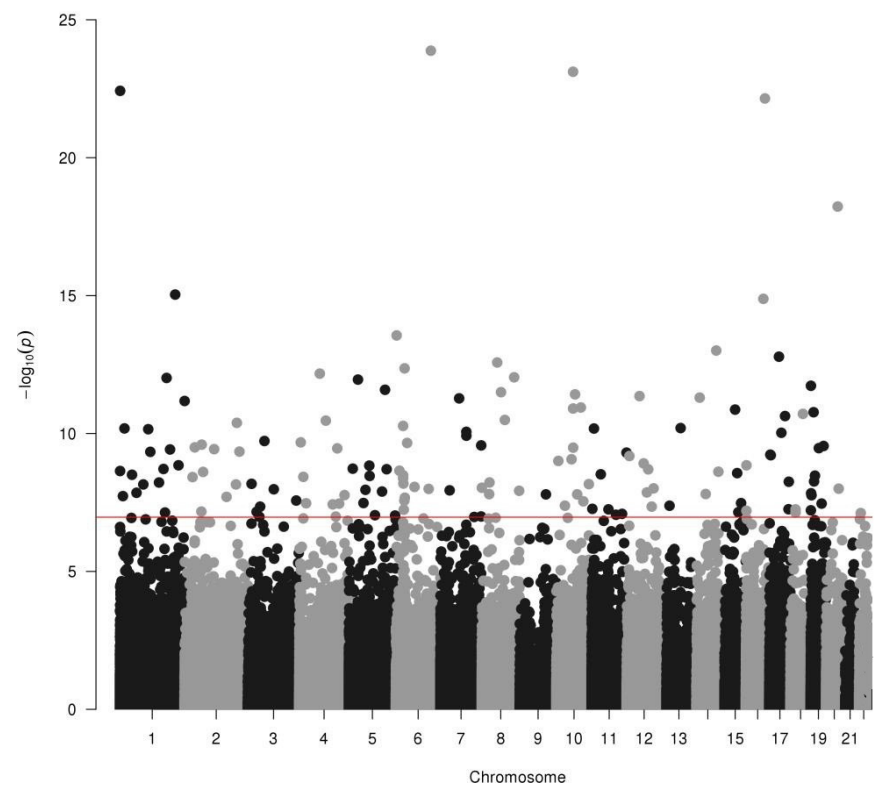

Figure 2 Results of the analysis of DNA methylation in children born to mother with rheumatoid arthritis (FEPRA study) compared with children born to women from the general population (Generation $R$ Study). The chromosomes are depicted on the $x$-axis, and the $-\log p$ value on the $y$-axis. The red line represents the Bonferroni threshold for a significance of $p=1.10 \times 10^{-7}$. FEPRA, FEtal Programming in Rheumatoid Arthritis.

mothers with RA than in those from the general population at all five CpGs with the lowest $\mathrm{p}$ values. Methylation at the five CpGs with the largest effect sizes was lower in children born to mothers with RA, with the exception of $\operatorname{cg} 06656994$.

\section{Subsequent analysis of DNA methylation}

The mean DAS28-CRP(3) in the first, second and third trimesters $(3.6,3.5$ and 3.3 , respectively) were highly correlated $(>0.6)$. The DAS28-CRP(3) in the third trimester was available in all patients. Therefore, this timepoint was chosen for

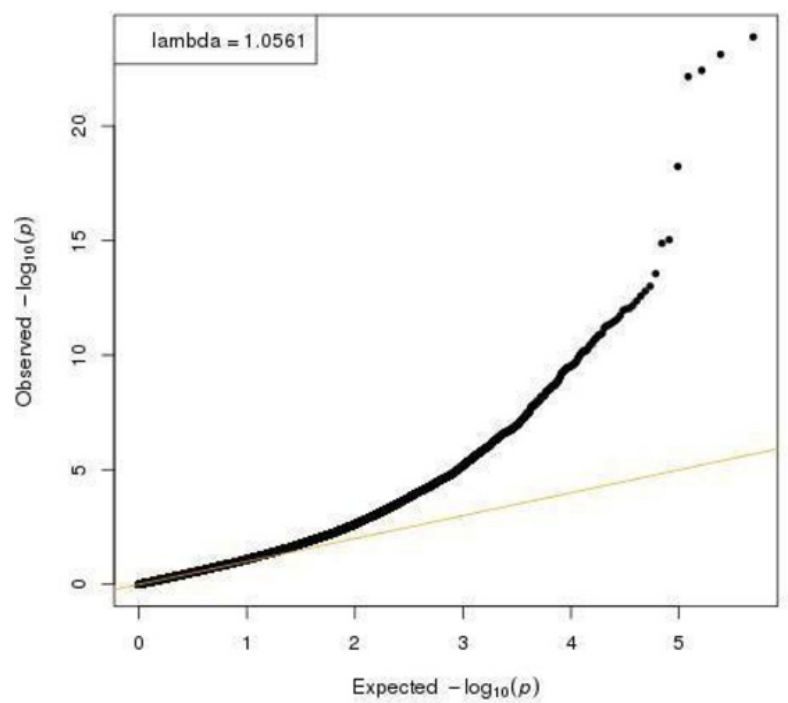

Figure 3 QQ plot of observed versus expected $p$ values from the analysis of DNA methylation in children born to mother with rheumatoid arthritis (FEPRA study) compared with children born to women from the general population (Generation R Study). FEPRA, FEtal Programming in Rheumatoid Arthritis. the analysis. None of the $147 \mathrm{CpGs}$ were significantly associated with maternal RA disease activity (DAS28-CRP(3)) in the third trimester or medication (prednisone or SSZ) use. In addition, none of the CpGs were associated with BMI SDS or fat percentage SDS in the children.

\section{Analysis in buccal epithelial cells}

A total of 10 out of the $147 \mathrm{CpGs}$ significantly associated with maternal RA in blood were also associated in buccal epithelial cells. From these, four were in the same direction as in blood (table 3). CpG cg11336323 was located in a promoter region.

\section{eQTM analysis}

Two CpGs, cg21384971 and cg11220663, were associated with expression of the COPZ2 and ADD2 genes, respectively (table 4). These two genes were also the nearest genes to those CpGs. ${ }^{45}$ Both CpGs were hypermethylated in the children born to mothers with RA and were associated with decreased expression of COPZ2 and ADD2 in the BIOS eQTM lookup browser.

\section{DISCUSSION}

This is the first study investigating the differences in DNA methylation of children born to mothers with RA compared with children born to mothers from the general population. In this unique study, all participants were followed prospectively from pregnancy onwards. Our study showed differential DNA methylation between the two groups. The differentially methylated CpG sites were not associated with disease activity and/or medication use, nor to BMI SDS and fat percentage SDS.

In total, $147 \mathrm{CpGs}$ were significantly associated with maternal RA after adjustment for multiple biological and technical covariates and hidden confounders. Of the five most significant CpGs, interestingly, two (cg06642177 and cg07786668) have been associated with myocardial infarction. ${ }^{47}$ The most significant $\mathrm{CpG}, \operatorname{cg} 06642177$, is located on chromosome 6 near the SLC2A12 gene, ${ }^{48}$ associated with insulin sensitivity, ${ }^{48} 49$ heart failure and diabetes ${ }^{50}$ in animal models. $\operatorname{cg} 07786668$, located on chromosome 16, is located in the ZFHX3 gene. ZFHX3 has been associated in multiple human studies with atrial fibrillation, ${ }^{51-55}$ coronary heart disease ${ }^{56}$ and obesity in a Korean population. ${ }^{57}$ cg20116574 was annotated to the NCOA5, a protein coding gene, which has been associated with diabetes mellitus type 2 in animal models. 5859

From the remaining $142 \mathrm{CpGs}, 1$ (cg17218495), annotated to the SMARCA4 gene, has independently and significantly been associated with myocardial infarction. ${ }^{47}$ The other significant CpGs from our study have not been associated with disease phenotypes.

Out of the initial 147 significant CpGs, 10 were also significantly differentially methylated in buccal epithelial cells obtained by cheek swabs. From these, four were in the same direction as in blood. When DNA methylation is altered in more than one germ layer derivate, it is likely that these alterations occurred in early development. ${ }^{21} 22$ These four CpGs have not been associated with disease phenotypes in humans. Unfortunately, in the Generation R Study, DNA methylation in buccal epithelial cells was not available. There were no publicly available epigenetic data sets on buccal epithelial cells in healthy children with a similar age and background.

As mentioned before, CpGs that are associated with eQTMs can influence the expression levels of genes. ${ }^{46}$ In our study, from the 147 significant CpGs, 2 were present in the BIOS QTL browser. cg21384971 is associated with less expression of the 
Table 2 The five most significant CpGs (white rows) and the five CpGs with the largest effect size (grey rows) from the linear mixed model: DNA methylation in blood samples from children born to mothers with RA (FEPRA study) compared with children born to mothers from the general population (Generation R Study)

\begin{tabular}{|c|c|c|c|c|c|c|c|}
\hline CpG & Beta* & SE & $P$ value & Nearest gene $( \pm b p)$ & Chr & bp & Locationt \\
\hline cg06642177 & 0.028 & 0.002 & $1.32 \times 10^{-24}$ & SLC2A12 (-122 529) & 6 & 134496341 & - \\
\hline cg08867893 & 0.018 & 0.002 & $7.66 \times 10^{-24}$ & ZNF365 (+221) & 10 & 64134160 & - \\
\hline cg06778273 & 0.024 & 0.002 & $3.77 \times 10^{-23}$ & TNFRSF18 $(+4995)$ & 1 & 1137117 & - \\
\hline cg20116574 & 0.019 & 0.002 & $5.91 \times 10^{-19}$ & NCOA5 $(+435)$ & 20 & 44718168 & Promoter \\
\hline cg16930947 & -0.050 & 0.008 & $3.22 \times 10^{-11}$ & - & 8 & 88984447 & - \\
\hline cg06656994 & 0.038 & 0.005 & $9.67 \times 10^{-13}$ & FAM163A (+903) & 1 & 179713176 & Enhancer \\
\hline $\operatorname{cg} 17483482$ & -0.037 & 0.006 & $4.62 \times 10^{-10}$ & - & 1 & 117152162 & - \\
\hline
\end{tabular}

*Beta represents the difference in DNA methylation at the given $\mathrm{CpG}$ site in children born to mothers with RA (FEPRA study) as compared with children born to mothers from the general population (Generation R Study).

tLocation in promoter, enhancer or unknown (-).

bp, base pair; Chr, chromosome; CpG, cytosine-phosphate-guanine; FEPRA, FEtal Programming in Rheumatoid Arthritis; RA, rheumatoid arthritis.

COPZ2 gene, which has been studied as a therapeutic opportunity for proliferation-independent selective killing of tumour cells. ${ }^{60} \mathrm{cg} 11220663$ is associated with less expression of the $A D D 2$ gene, also known as beta-adducin. $A D D 2$ is involved in multiple pathogenic processes with a wide range of diseases. ${ }^{61}$ ADD2 gene variants are associated with hypertension, ${ }^{62}$ cancer $^{61}$ and systemic lupus erythematosus. ${ }^{63}$

Pathway analysis of the genes annotated to the 147 significant CpGs, using the WebGestalt (WEB-based Gene Set AnaLysis Toolkit), ${ }^{64}$ did not result in significant pathways (data not shown).

Thus, some of the associated CpGs (cg06642177, $\operatorname{cg} 07786668$ and $\operatorname{cg} 17218495)$ have been associated with cardiovascular disease in previous studies, while others are located in or near genes that are associated with cardiovascular or metabolic disease. Maternal RA during pregnancy, a chronic inflammatory disease, might be associated with later-life health and disease risk in the offspring.

None of the significant CpGs were associated with RA disease activity or medication use during pregnancy. However, this may have been due to a lack of power, since these analyses were performed in the 80 samples of the children born to women with RA. The same power problem also applied to the analysis of the CpGs with indicators for future metabolic and cardiovascular disease (BMI SDS and fat percentage).

Remarkably, a large percentage of women with RA did not use folic acid before or during pregnancy. Even though this is outside the scope of our study, this requires additional attention during preconceptional counselling.
Our study has some limitations. First, although in its kind it is a large study, a study on DNA methylation including 80 subjects and 354 controls is still relatively small. Despite this, a large number of $\mathrm{CpGs}$ reached significance. Correcting for biological and technical covariates, as well as hidden confounders, and using $B A C O N$ resulted in a $\lambda$ near 1 , reflecting that there was no inflation. Second, we were not able to collect a new independent cohort of children born to mothers with RA to replicate the results. At the time our study was performed, there were no other comparable prospective studies available. Currently, European research groups are conducting new prospective cohort studies on the impact of RA on pregnancy and offspring. We encourage these research groups, possibly with international collaborations, to replicate our study.

Thus, the results of this study may support follow-up research of children born to mothers with RA. Based on our data, we recommend that at least indicators for future cardiovascular and metabolic disease should be considered. The effects of RA disease activity and medication use on DNA methylation should be investigated in studies with larger sample sizes. Furthermore, in the last years the use of tumour necrosis factor (TNF) inhibitors during pregnancy in patients with RA has increased. This often results in lower RA disease activity during pregnancy. Future research should also cover the effects of the use of TNF inhibitors on the differentially methylated CpGs in children born to mothers with RA.

In addition, it would be interesting for a future study to measure DNA methylation in the mothers of the children from our study and compare that with the methylation of their offspring. Since

Table 3 CpGs that were differentially methylated in the same direction in both blood and in buccal epithelial cells

\begin{tabular}{llllllll}
\hline CpG & Beta* & SE & P value & $\begin{array}{l}\text { Nearest gene } \\
( \pm \text { bp })\end{array}$ & Chr & bp & Locationt \\
\hline cg22998206 & 0.1029 & 0.022 & $4.40 \times 10^{-06}$ & - & 12 & 49239429 & - \\
cg03654106 & 0.0727 & 0.016 & $9.50 \times 10^{-06}$ & - & 19 & 49539527 & - \\
cg02613964 & -0.058 & 0.014 & $7.57 \times 10^{-05}$ & - & 3 & 44690321 & - \\
cg11336323 & -0.092 & 0.024 & $1.63 \times 10^{-04}$ & - & 19 & 41946040 & Promoter \\
\hline
\end{tabular}

*Beta represents the difference in DNA methylation at the given CpG site in buccal epithelial cells from children born to mothers with RA (FEPRA study) as compared with blood samples from children born to mothers from the general population (Generation R Study).

tLocation in promoter, gene, enhancer or unknown (-).

bp, base pair; Chr, chromosome; CpG, cytosine-phosphate-guanine; FEPRA, FEtal Programming in Rheumatoid Arthritis; RA, rheumatoid arthritis. 
Table 4 Results from the eQTM analysis using the $147 \mathrm{CpGs}$ significantly different in children born to mothers with RA (FEPRA study)

\begin{tabular}{|c|c|c|c|c|c|c|c|c|}
\hline CpG & Beta* & $\mathrm{SE}^{*}$ & P value* & Nearest genes & Beta GN† & SE GN† & $P$ value GN $\dagger$ & $\begin{array}{l}\text { Genes } \\
\text { GNt }\end{array}$ \\
\hline cg21384971 & 0.029 & 0.004 & $3.86 \times 10^{-13}$ & COPZ2 & -0.073 & 0.039 & $1.79 \times 10^{-06}$ & COPZ2 \\
\hline cg11220663 & 0.023 & 0.003 & $1.68 \times 10^{-11}$ & $A D D 2$ & -0.121 & 0.039 & $3.32 \times 10^{-06}$ & ADD2 \\
\hline
\end{tabular}

The positive betas in column 'Beta' represent hypermethylation, while the negative betas in column 'Beta GN' represent decreased gene expression.

${ }^{*}$ The columns beta, $\mathrm{SE}, \mathrm{p}$ value and nearest genes represent the results from the analysis of DNA methylation in children born to mothers with RA (FEPRA study) as compared with children born to mothers from the general population (Generation R Study).

tThe columns beta GN, SE GN, p value GN and genes GN represent the results from the BIOS eQTM lookup browser.

CpG, cytosine-phosphate-guanine; eQTM, expression quantitative trait methylation; FEPRA, FEtal Programming in Rheumatoid Arthritis; GN, GeneNetwork; RA, rheumatoid arthritis.

mothers and children live in a shared environment (generally), there may be an overlap in differentially methylated CpGs.

In conclusion, maternal RA during pregnancy is associated with differential DNA methylation in offspring. It remains unknown whether the identified associations are causal, and if so whether they are caused by the disease or treatment. Some of the differentially methylated CpGs or their nearby genes were associated with cardiovascular or metabolic disease. Maternal RA disease might have lifelong consequences for the offspring. However, more research in this particular field must be undertaken in order to strengthen the relevance of our findings.

\section{Author affiliations}

'Department of Rheumatology, Erasmus MC, University Medical Center Rotterdam, Rotterdam, The Netherlands

${ }^{2}$ Department of Internal Medicine, Erasmus MC, University Medical Center Rotterdam, Rotterdam, The Netherlands

${ }^{3}$ The Generation R Study Group, Erasmus MC, University Medical Center Rotterdam, Rotterdam, The Netherlands

${ }^{4}$ Department of Epidemiology, Erasmus MC, University Medical Center Rotterdam, Rotterdam, The Netherlands

${ }^{5}$ Department of Pediatrics, Erasmus MC, University Medical Center Rotterdam,

Rotterdam, The Netherlands

${ }^{6}$ Department of Pediatrics, Division of Respiratory Medicine and Allergology, Erasmus MC, University Medical Center Rotterdam, Rotterdam, The Netherlands

${ }^{7}$ Department of Pediatrics, Division of Neonatology, Erasmus MC, University Medical Center Rotterdam, Rotterdam, The Netherlands

Correction notice This article has been corrected since it first published online. The open access licence type has been amended.

Acknowledgements We are grateful to all patients participating in the PARA study, FEPRA study and the Generation R Study. We thank all research assistants and laboratory workers for their help with data collection and processing of the samples. We gratefully acknowledge the contribution of Dr Florentien de Steenwinkel for her work on the FEPRA study. We thank Dr Bas Heijmans for his advice on the statistica analysis of the data. The Generation R Study is conducted by the Erasmus Medical Centre in close collaboration with the School of Law and Faculty of Social Sciences of the Erasmus University Rotterdam, the Municipal Health Service Rotterdam area, Rotterdam, the Rotterdam Homecare Foundation, Rotterdam, and the Stichting Trombosedienst \& Artsenlaboratorium Rijnmond (STAR-MDC), Rotterdam. We gratefully acknowledge the contribution of children and parents, general practitioners, hospitals, midwives and pharmacies in Rotterdam. The generation and management of the Illumina 450K methylation array data (EWAS data) for the Generation R Study were executed by the Human Genotyping Facility of the Genetic Laboratory of the Department of Internal Medicine, Erasmus MC, the Netherlands. We thank Mr Michael Verbiest, Ms Mila Jhamai, Ms Sarah Higgins, Mr Marijn Verkerk and Dr Lisette Stolk for their help in creating the EWAS database. We thank Dr A Teumer for his work on the quality control and normalisation scripts.

Contributors JMH, RJEMD, JBVM, JF, LD, HI-A: study design and analysis plan. JMH, RJEMD, JF: data acquisition. HI-A, PM, JF: cleaning of data. PM, HI-A: data analysis. HI-A, RJEMD: draft paper. JMH, RJEMD, JF, JBvM, PM, LD, HI-A: revision of the paper and final approval for publication. The authors confirm that they all meet the Uniform Requirements for Manuscripts Submitted to Biomedical Journals criteria for authorship.

Funding This study was funded by the Dutch Arthritis Society (ReumaNederland), a non-commercial fund-raising organisation. The general design of the Generation $\mathrm{R}$ Study is made possible by financial support from the Erasmus Medical Centre, Rotterdam, the Erasmus University Rotterdam, the Netherlands Organisation for Health Research and Development, and the Ministry of Health, Welfare and Sport.
The EWAS data was funded by a grant to Vincent W Jaddoe (Generation R Study group) from the Netherlands Genomics Initiative (NGI)/Netherlands Organisation for Scientific Research (NWO), Netherlands Consortium for Healthy Ageing (NCHA; project nr 050-060-810), by funds from the Genetic Laboratory of the Department of Internal Medicine, Erasmus MC, and by a grant from the National Institute of Child and Human Development (R01HD068437). LD received funding from the European Union's Horizon 2020 cofunded programme ERA-Net on Biomarkers for Nutrition and Health (ERA HDHL) (ALPHABET project (no 696295; 2017), ZonMW The Netherlands (no 529051014; 2017)). The Generation R Study was supported by funding from the European Union's Horizon 2020 research and innovation programme (733206, LifeCycle Project).

Competing interests None declared.

Patient consent for publication Not required.

Ethics approval This study is in compliance with the Helsinki Declaration. Informed consent was obtained for all participants. The Medical Ethics Committee of Erasmus MC, University Medical Center Rotterdam, the Netherlands, approved the PARA study (MEC-214.320/2002/117), FEPRA study (MEC-2009-441) and the Generation R Study (MEC 198.782.2001.31).

Provenance and peer review Not commissioned; externally peer reviewed. Data availability statement Data may be obtained from a third party and are not publicly available.

Open access This is an open access article distributed in accordance with the Creative Commons Attribution 4.0 Unported (CC BY 4.0) license, which permits others to copy, redistribute, remix, transform and build upon this work for any purpose, provided the original work is properly cited, a link to the licence is given, and indication of whether changes were made. See: https://creativecommons.org/ licenses/by/4.01.

\section{REFERENCES}

1 Barouki R, Gluckman PD, Grandjean P, et al. Developmental origins of noncommunicable disease: implications for research and public health. Environ Health 2012;11.

2 Barker DJP. Fetal origins of cardiovascular disease. Ann Med 1999;31:3-6.

3 Ong KK, Dunger DB. Perinatal growth failure: the road to obesity, insulin resistance and cardiovascular disease in adults. Best Pract Res Clin Endocrinol Metab 2002;16:191-207.

4 Painter RC, de Rooij SR, Bossuyt PM, et al. Early onset of coronary artery disease after prenatal exposure to the Dutch famine. Am J Clin Nutr 2006:84:322-7.

5 Stein AD, Kahn HS, Rundle A, et al. Anthropometric measures in middle age after exposure to famine during gestation: evidence from the Dutch famine. Am J Clin Nutr 2007:85:869-76.

6 Turan N, Ghalwash MF, Katari S, et al. DNA methylation differences at growth related genes correlate with birth weight: a molecular signature linked to developmental origins of adult disease? BMC Med Genomics 2012;5

7 Hogg K, Price EM, Hanna CW, et al. Prenatal and perinatal environmental influences on the human fetal and placental epigenome. Clin Pharmacol Ther 2012;92:716-26.

8 Jin B, Li Y, Robertson KD. DNA methylation: superior or subordinate in the epigenetic hierarchy? Genes Cancer 2011;2:607-17.

9 Day K, Waite LL, Thalacker-Mercer A, et al. Differential DNA methylation with age displays both common and dynamic features across human tissues that are influenced by CpG landscape. Genome Biol 2013;14.

10 Heijmans BT, Tobi EW, Stein AD, et al. Persistent epigenetic differences associated with prenatal exposure to famine in humans. Proc Natl Acad Sci U S A 2008;105:17046-9.

11 Tobi EW, Lumey LH, Talens RP, et al. DNA methylation differences after exposure to prenatal famine are common and timing- and sex-specific. Hum Mol Genet 2009;18:4046-53.

12 Tobi EW, Goeman JJ, Monajemi R, et al. DNA methylation signatures link prenatal famine exposure to growth and metabolism. Nat Commun 2014;5. 
13 Tobi EW, Slieker RC, Luijk R, et al. DNA methylation as a mediator of the association between prenatal adversity and risk factors for metabolic disease in adulthood. Sci Adv 2018;4:eaao4364.

14 Joubert BR, Håberg SE, Nilsen RM, et al. 450K epigenome-wide scan identifies differential DNA methylation in newborns related to maternal smoking during pregnancy. Environ Health Perspect 2012;120:1425-31.

15 Park JH, Stoffers DA, Nicholls RD, et al. Development of type 2 diabetes following intrauterine growth retardation in rats is associated with progressive epigenetic silencing of Pdx1. J Clin Invest 2008;118:2316-24.

16 Crudo A, Petropoulos S, Moisiadis VG, et al. Prenatal synthetic glucocorticoid treatment changes DNA methylation states in male organ systems: multigenerational effects. Endocrinology 2012;153:3269-83.

17 Glier MB, Green TJ, Devlin AM. Methyl nutrients, DNA methylation, and cardiovascular disease. Mol Nutr Food Res 2014;58:172-82.

18 Foran E, Garrity-Park MM, Mureau C, et al. Upregulation of DNA methyltransferasemediated gene silencing, anchorage-independent growth, and migration of colon cancer cells by interleukin-6. Mol Cancer Res 2010:8:471-81.

19 Ruemmele FM, Garnier-Lengliné $H$. Why are genetics important for nutrition? Lessons from epigenetic research. Ann Nutr Metab 2012;60 Suppl 3(Suppl 3):38-43.

20 Slieker RC, Bos SD, Goeman JJ, et al. Identification and systematic annotation of tissue-specific differentially methylated regions using the Illumina 450k array. Epigenetics Chromatin 2013;6.

21 Seisenberger S, Andrews S, Krueger F, et al. The dynamics of genome-wide DNA methylation reprogramming in mouse primordial germ cells. Mol Cell 2012;48:849-62.

22 Seisenberger S, Peat JR, Hore TA, et al. Reprogramming DNA methylation in the mammalian life cycle: building and breaking epigenetic barriers. Philos Trans $R$ Soc Lond B Bio/ Sci 2013:368

23 de Man YA, Hazes JMW, van der Heide $\mathrm{H}$, et al. Association of higher rheumatoid arthritis disease activity during pregnancy with lower birth weight: results of a national prospective study. Arthritis Rheum 2009;60:3196-206

24 Järnerot G, Into-Malmberg MB, Esbjörner E. Placental transfer of sulphasalazine and sulphapyridine and some of its metabolites. Scand J Gastroenterol 1981;16:693-7

25 D'Anna-Hernandez KL, Ross RG, Natvig CL, et al. Hair cortisol levels as a retrospective marker of hypothalamic-pituitary axis activity throughout pregnancy: comparison to salivary cortisol. Physiol Behav 2011;104:348-53.

26 Benediktsson R, Calder AA, Edwards CR, et al. Placental 11 beta-hydroxysteroid dehydrogenase: a key regulator of fetal glucocorticoid exposure. Clin Endocrinol 1997;46:161-6.

27 Burton PJ, Waddell BJ. Dual function of 11 beta-hydroxysteroid dehydrogenase in placenta: modulating placental glucocorticoid passage and local steroid action. Biol Reprod 1999:60:234-40.

28 de Steenwinkel FDO, Hokken-Koelega ACS, Hazes JMW, et al. The influence of foetal prednisone exposure on the cortisol levels in the offspring. Clin Endocrinol 2014;80:804-10.

29 de Man YA, Dolhain RJEM, van de Geijn FE, et al. Disease activity of rheumatoid arthritis during pregnancy: results from a nationwide prospective study. Arthritis Rheum 2008;59:1241-8.

30 Ince-Askan H, Hazes JMW, Dolhain RJEM. Is disease activity in rheumatoid arthritis during pregnancy and after delivery predictive for disease activity in a subsequent pregnancy? J Rheumatol 2016;43:22-5.

31 Ince-Askan $\mathrm{H}$, Hazes JMW, Dolhain RJEM. Identifying clinical factors associated with low disease activity and remission of rheumatoid arthritis during pregnancy. Arthritis Care Res. In Press 2017:69:1297-303.

32 Kooijman MN, Kruithof CJ, van Duijn CM, et al. The Generation R Study: design and cohort update 2017. Eur J Epidemiol 2016;31:1243-64.

33 de Steenwinkel FDO, Dolhain RJEM, Hazes JMW, et al. Does prednisone use or disease activity in pregnant women with rheumatoid arthritis influence the body composition of their offspring? Reprod Toxicol 2017;71:118-23.

34 Lehne B, Drong AW, Loh $\mathrm{M}$, et al. A coherent approach for analysis of the Illumina HumanMethylation450 BeadChip improves data quality and performance in epigenome-wide association studies. Genome Biol 2015;16.

35 Houseman EA, Accomando WP, Koestler DC, et al. DNA methylation arrays as surrogate measures of cell mixture distribution. BMC Bioinformatics 2012;13.

36 Reinius $L E$, Acevedo $N$, Joerink $M$, et al. Differential DNA methylation in purified human blood cells: implications for cell lineage and studies on disease susceptibility. PLoS One 2012;7:e41361.
37 Gruzieva O, Xu C-J, Breton CV, et al. Epigenome-wide meta-analysis of methylation in children related to prenatal NO2 air pollution exposure. Environ Health Perspect 2017;125:104-10.

38 Reese SE, Xu C-J, den Dekker HT, et al. Epigenome-wide meta-analysis of DNA methylation and childhood asthma. J Allergy Clin Immunol. In Press 2018. doi:10.1016/j.jaci.2018.11.043. [Epub ahead of print: 21 Dec 2018].

39 Bonder MJ, Luijk R, Zhernakova DV, et al. Disease variants alter transcription factor levels and methylation of their binding sites. Nat Genet 2017;49:131-8.

40 Joubert BR, Felix JF, Yousefi P, et al. DNA methylation in newborns and maternal smoking in pregnancy: genome-wide Consortium meta-analysis. Am J Hum Genet 2016:98:680-96.

41 Wang J, Zhao Q, Hastie T. Confounder adjustment in multiple hypothesis testing. arXiv:150804178, 2015. Available: https://arxiv.org/abs/1508.04178

42 van Iterson M, van Zwet EW, Heijmans BT, et al. Controlling bias and inflation in epigenome- and transcriptome-wide association studies using the empirical null distribution. Genome Biol 2017;18.

43 Devlin B, Roeder K. Genomic control for association studies. Biometrics 1999;55:997-1004.

44 Bland JM, Altman DG. Multiple significance tests: the Bonferroni method. BMJ 1995:310:170

45 McLean CY, Bristor D, Hiller M, et al. Great improves functional interpretation of cisregulatory regions. Nat Biotechnol 2010;28:495-501.

46 Jones MJ, Fejes AP, Kobor MS. DNA methylation, genotype and gene expression: who is driving and who is along for the ride? Genome Biol 2013:14.

47 Nakatochi M, Ichihara S, Yamamoto K, et al. Epigenome-wide association of myocardial infarction with DNA methylation sites at loci related to cardiovascular disease. Clin Epigenetics 2017;9.

48 Matsuzaka T, Shimano H. GLUT12: a second insulin-responsive glucose transporters as an emerging target for type 2 diabetes. J Diabetes Investig 2012;3:130-1.

49 Purcell SH, Aerni-Flessner LB, Willcockson AR, et al. Improved insulin sensitivity by GLUT12 overexpression in mice. Diabetes 2011;60:1478-82.

50 Jiménez-Amilburu V, Jong-Raadsen S, Bakkers J, et al. GLUT12 deficiency during early development results in heart failure and a diabetic phenotype in zebrafish. $J$ Endocrinol 2015;224:1-15.

51 Benjamin EJ, Rice KM, Arking DE, et al. Variants in ZFHX3 are associated with atrial fibrillation in individuals of European ancestry. Nat Genet 2009;41:879-81.

52 Li C, Wang F, Yang Y, et al. Significant association of SNP rs2106261 in the ZFHX3 gene with atrial fibrillation in a Chinese Han GenelD population. Hum Genet 2011;129:239-46.

53 Liu Y, Ni B, Lin Y, et al. Genetic polymorphisms in ZFHX3 are associated with atrial fibrillation in a Chinese Han population. PLoS One 2014;9:e101318.

$54 \mathrm{Kao}$ Y-H, Hsu J-C, Chen Y-C, et al. ZFHX3 knockdown increases arrhythmogenesis and dysregulates calcium homeostasis in $\mathrm{HL}-1$ atrial myocytes. Int J Cardiol 2016:210:85-92.

55 Zaw KTT, Sato N, Ikeda S, et al. Association of ZFHX3 gene variation with atrial fibrillation, cerebral infarction, and lung thromboembolism: an autopsy study. $J$ Cardiol 2017;70:180-4

56 Sun $\mathrm{S}$, Zhang W, Chen $\mathrm{X}$, et al. The CAA repeat polymorphism in the ZFHX3 gene is associated with risk of coronary heart disease in a Chinese population. Tohoku J Exp Med 2015:235:261-6.

57 Yang S-A. Association study between ZFHX3 gene polymorphisms and obesity in Korean population. J Exerc Rehabil 2017;13:491-4.

58 Gao S, Li A, Liu F, et al. NCOA5 haploinsufficiency results in glucose intolerance and subsequent hepatocellular carcinoma. Cancer Cell 2013;24:725-37.

59 Liu CY, Feng G-S. NCOA5, a molecular link between type 2 diabetes and liver cancer. Hepatobiliary Surg Nutr 2014;3:106-8.

60 Shtutman M, Baig M, Levina $\mathrm{E}$, et al. Tumor-specific silencing of COPZ2 gene encoding coatomer protein complex subunit $\zeta 2$ renders tumor cells dependent on its paralogous gene COPZ1. Proc Natl Acad Sci U S A 2011:108:12449-54.

61 Kiang KM-Y, Leung GK-K. A review on adducin from functional to pathological mechanisms: future direction in cancer. Biomed Res Int 2018:2018:1-14.

62 Marcun Varda N, Zagradisnik B, Herodez SS, et al. Polymorphisms in four candidate genes in young patients with essential hypertension. Acta Paediatr 2006:95:353-8.

63 Ramirez GA, Lanzani C, Bozzolo EP, et al. Beta-adducin and sodium-calcium exchanger 1 gene variants are associated with systemic lupus erythematosus and lupus nephritis. Rheumatol Int 2015:35:1975-83.

64 Wang J, Duncan D, Shi Z, et al. Web-based gene set analysis toolkit (WebGestalt): update 2013. Nucleic Acids Res 2013:41:W77-W83. 